\title{
Association between Lifestyle and Academic Performance among Medical Students, Majmaah, Saudi Arabia
}

\author{
Usama Bin Ghaffar ${ }^{1}$, Waqas Sami², Abdulrahman Abbas Aldawsari ${ }^{3}$, Mamdouh Mohammedalazmi ${ }^{4}$, \\ Hatem Abdullah Okasi ${ }^{5}$, Ahmad Abdullah Alsaleh ${ }^{6}$, Abdulaziz Muqhim Alshammari ${ }^{7}$ Ali Faraz ${ }^{8}$ \\ ${ }^{1}$ Department of Pathology, College of Medicine, Majmaah University, Al-Majmaah 11952, Saudi Arabia. \\ ${ }^{2}$ Department of Community Medicine \& Public Health, College of Medicine, Majmaah University, Al-Majmaah 11952, \\ Saudi Arabia. ${ }^{3}$ College of Medicine, Majmaah University, Al-Majmaah 11952, Saudi Arabia. ${ }^{4}$ College of Medicine, \\ Majmaah University, Al-Majmaah 11952, Saudi Arabia. ${ }^{5}$ College of Medicine, Majmaah University, Al-Majmaah 11952, \\ Saudi Arabia. ${ }^{6}$ College of Medicine, Majmaah University, Al-Majmaah 11952, Saudi Arabia. \\ ${ }^{7}$ College of Medicine, Majmaah University, Al-Majmaah 11952, Saudi Arabia. ${ }^{8}$ Department of Pathology, College of \\ Medicine, Majmaah University, Al-Majmaah 11952, Saudi Arabia.
}

\section{ABSTRACT}

\section{BACKGROUND}

A healthy lifestyle includes practices such as proper nutrition, regular exercise, adequate hours of sleep, and avoiding substance abuse. Many research projects have shown that there is a correlation between lifestyle and academic performance, while others found that lifestyle is not consistent with academic achievement. We wanted to examine the association between lifestyle and academic performance among medical students of Majmaah University, Saudi Arabia.

\section{METHODS}

This is a cross-sectional study, and a survey was carried out amongst the students attending college of medicine, Majmaah University, through a well-designed pretested questionnaire. Data were analysed using SPSS software.

\section{RESULTS}

A total of 171 medical students participated in the study. Most of the participants $n=$ $119(69.6 \%)$ were males, and the rest $n=52(30.4 \%)$ were females. The mean age of participants was $(21.64 \pm 1.88)$ based on the results; most of the participants $n=101$ (59\%) were between the $2^{\text {nd }}$ and $3^{\text {rd }}$ academic years. The academic performance of the students did not correlate with the lifestyle habits of the students. Lifestyle parameters tested were physical activity, dietary habits, sleeping patterns, substance abuse, and the use of social media. Academic performance was measured using the cumulative grade point average (GPA) of the student. No statistically significant difference regarding academic performance was noted among the high GPA and low GPA students in relation to their lifestyle. None of the healthy behaviours like physical activity, dietary habits, sleep patterns, and substance abuse are related to the academic performance of medical students $(p>0.05)$.

\section{CONCLUSIONS}

Our study showed that there was no association between lifestyle and academic performance.

\section{KEY WORDS}

Physical Activities, Dietary Habits, Lifestyle, Academic Performance
Corresponding Author: Dr. Usama Bin Ghaffar, Assistant Professor, Department of Pathology, College of Medicine, Majmaah University, Al-Majmaah, Kingdom of Saudi Arabia. E-mail: ubghaffar@gmail.com

DOI: 10.14260/jemds/2020/345

Financial or Other Competing Interests: None.

How to Cite This Article: Ghaffar UB, Sami W, Aldawsari AA, et al. Association between lifestyle and academic performance among medical students, Majmaah, Saudi Arabia. J. Evolution Med. Dent. Sci. 2020;9(20):1579-1584, DOI: $10.14260 /$ jemds/2020/345

Submission 10-03-2020,

Peer Review 28-04-2020,

Acceptance 04-05-2020,

Published 18-05-2020. 


\section{BACKGROUND}

A healthy lifestyle, as defined by WHO, is a way of life, that lowers the risk of being seriously ill or dying early.[1] Practicing healthy habits can reduce the risk of having many diseases and help improve and maintain quality of life. A healthy lifestyle includes practices such as proper nutrition, regular exercise, having adequate hours of sleep, and avoiding smoking and substance abuse. Also, having a healthy diet and avoiding the use of harmful substances such as drugs, tobacco, and alcohol improves physical and mental health. Studies have shown that unhealthy lifestyle behaviours have a positive relationship with poor academic achievement.[2,3] In fact, healthy students are great learners and being healthier means that their minds and bodies work as they should

An unhealthy lifestyle includes: physical inactivity, skipping breakfast, eat junk food, Sleep deprivation, smoking cigarettes, drinking too much alcohol, addiction to gadgets, prolong use of smart phone.[2] Lifestyle is a way of life for people who display it daily in their physical, psychological, social, and economic environment. Lifestyle is expressed in both work and leisure behaviour patterns and (on an individual basis) in activities, attitudes, interests, opinions, values, and allocation of income. It also reflects people's selfimage or self-concept, the way they see themselves and believe the others see them. Lifestyle is a composite of motivations, needs, and wants and is influenced by factors such as culture, family, reference groups, and social class. ${ }^{[4]}$

Implementation of academic programs requires real awareness of the variables influencing the lifestyle of the students. The educational performance level is one of the progress indicators of scientific activities in every educational system. Studies have found that in addition to the educational curriculum, various lifestyle factors influence educational performance.(2) With a GDP per capita of about 22,000 US dollars, Saudi Arabia is classified as a high-income country. Although it regulated infectious diseases and infant mortality effectively, the so-called "ill effects of civilization" have taken centre stage.(5) Saudi Arabia ranks $3^{\text {rd }}$ in the world in terms of laziness and obesity.(6) Unhealthy lifestyle among Saudi medical students could impact patient care in the future. Thus the goal of this study was to examine the relationship between lifestyle and student academic achievement, hypothesizing that the quality of life is directly proportional to the academic performance of students.

\section{METHODS}

This is a cross-sectional study conducted among 171 medical students of College of Medicine, Majmaah University, Saudi Arabia from October 2018 to April 2019. Data was collected by a pre-tested and self-administered questionnaire. The questionnaire included the demographic characteristics of the students. It also included questions about their GPA and lifestyle habits.

\section{Data Analysis}

Data were analysed using statistical package for social sciences (SPSS). A comparison between qualitative data was made by the Chi-square test, and p-value $<0.05$ was considered as significant.

\section{Ethical Considerations}

Ethics approval was obtained from the ethics committee of Majmaah University. Informed consent was obtained from the participants, and all collected data were kept confidential and will be used only for this study purpose.

\section{RESULTS}

\section{Descriptive Analysis}

A total of 171 medical students participated in the study. The study showed that most of the participants $n=119(69.6 \%)$ were males and the rest $n=52(30.4 \%)$ were females. The mean age of participants was $(21.64 \pm 1.88)$ based on the results; most of the participants $n=101$ (59\%) were between the $2^{\text {nd }}$ and $3^{\text {rd }}$ academic years. In addition, the majority of participants $n=92(53.8 \%)$ were living in Majmaah. Regarding marital status out of 171 participants, 166 participants (97.1\%) were single. Furthermore, a large number of participants, $\mathrm{n}=96(56.1 \%)$, reported having normal BMI. Out of 171 participants, $n=37(21.6 \%)$ of them had a GPA score from $5-4.5, \mathrm{n}=29(17.0 \%)$ had a score from $4.49-4, \mathrm{n}=57$ (33.3\%) had a score from $3.99-3.5$ and $n=48$ (28.1\%) had a score less than 3.5 .

Table- 1 of the study showed that most of the participants $\mathrm{n}=77$ (45\%) reported that they had 7-9 Sleeping hours per day, and almost half of the participants $n=83(48.5 \%)$ had $1-3$ times of physical activity per week. The majority of the participants $n=62(36.3 \%)$ said they spent $15-30$ minutes on exercise per day, $n=71(41.5 \%)$ said they are having three meals per day, $\mathrm{n}=47(27.5 \%)$ rarely had breakfast every day. Also, $n=66(38.6 \%)$ are seldom having a recommended daily amount of fruits and vegetables. Many of the participants $\mathrm{n}=62(36.3 \%)$ are eating fast food per week, $\mathrm{n}=79(46.2 \%)$ drink coffee, tea, and energy drinks per week, and $n=145$ $(84.4 \%)$ smoke cigarettes per day. Over half of the participants $n=100(58.5 \%)$ reported that they are using the computer, cell phone or internet for leisure time more than 4 hours per day, and almost one-third $n=56(32.7 \%)$ said that they are watching TV, movies and playing video games 1-2 hours per day.

\section{Inferential Analysis}

Table- 2 of our study showed that male students with high GPA 5-4.5 were 22 (59.5\%), and female students were 15 (40.5\%), and those with lowest GPA $<3.5$ in males were 38 (79.2\%) and females were 10 (20.8\%). Regarding marital status, those who were single having GPA 5-4.5 were 36 (97.3\%), and those having GPA $<3.5$ and single are 46 (95.8\%). 36 (97.3\%) of those who have GPA 5-4.5 were single, and $1(2.7 \%)$ were divorced, and $46(95.8 \%)$ of those who have GPA $<3.5$ were single, and $2(4.2 \%)$ were married. Also, 19 (51.4\%) of the participants who have GPA 5-4.5 were living in Majmaah, 5 (13.5\%) were living in Riyadh, 5 (13.5) were residing in Zulfi, and 8 (21.6\%) live in other cities and $25(52.1 \%)$ of those with GPA $<3.5$ were living in Majmaah, 15 (31.3\%) were living in Riyadh, 4 (8.3\%) were living in Zulfi and $4(8.3 \%)$ are living in other cities. Moreover, 16 
$(43.2 \%)$ of the participants who have GPA 5-4.5 were $2^{\text {nd }}$ -

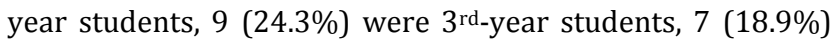
were $4^{\text {th }}$-year students and only $5(13.5 \%)$ were $5^{\text {th }}$-year students and those who have GPA $<3.5$ were $16(33.3 \%)$ of them were $2^{\text {nd-year }}$ students, $14(29.2 \%)$ were $3^{\text {rd-year }}$ students, 7 (14.6\%) were $4^{\text {th }}$-year students, and 11 (22.9\%) were $5^{\text {th }}$-year students.

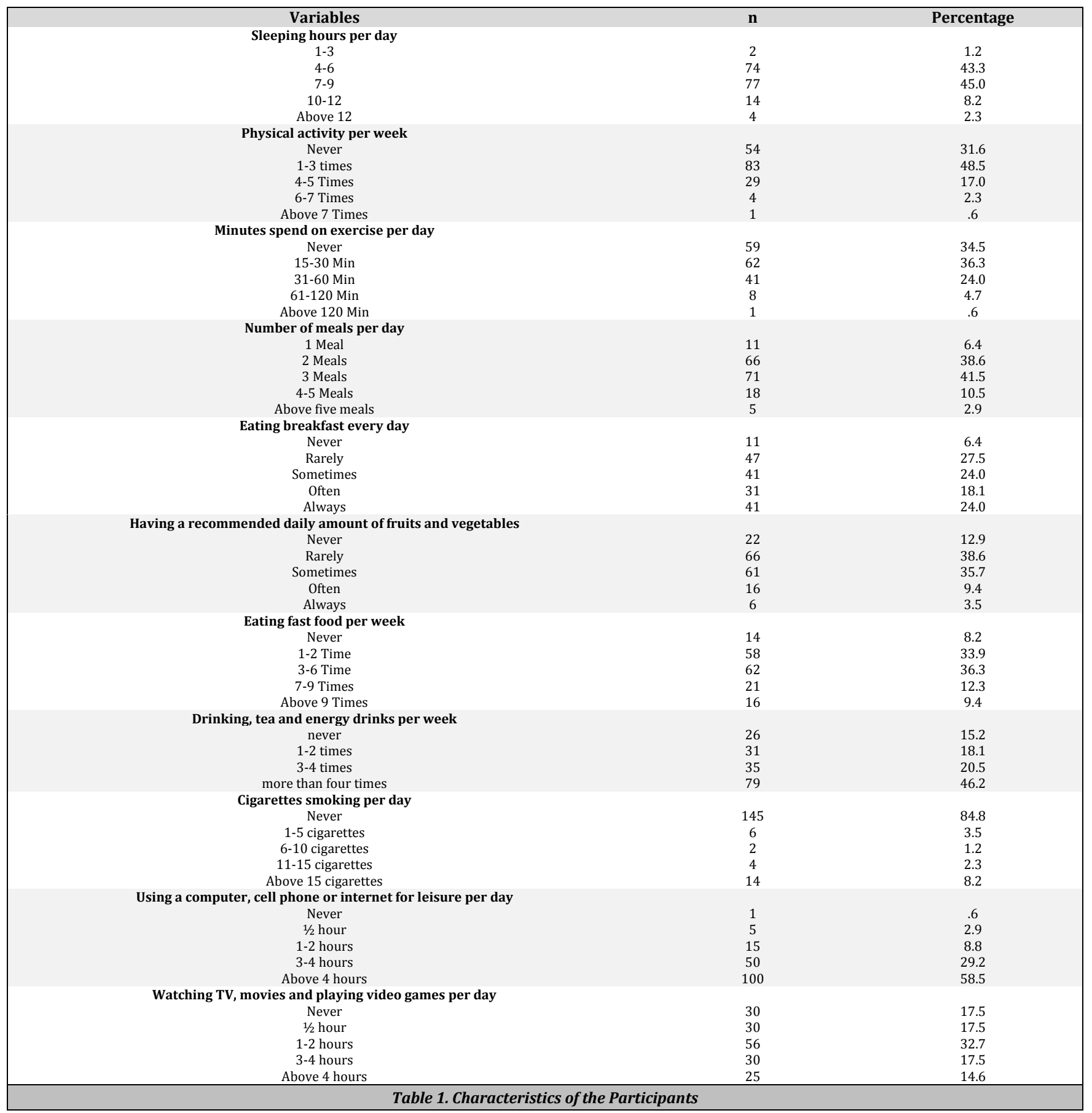

\begin{tabular}{|c|c|c|c|c|c|c|c|}
\hline \multicolumn{2}{|c|}{ Demographic Characteristics } & $5-4.5$ & $4.49-4$ & $\begin{array}{c}\text { GPA } \\
3.99-3.5\end{array}$ & $<3.5$ & Total & \multirow{2}{*}{$\begin{array}{c}\text { Chi-Square } \\
\text { p-Value } \\
0.263\end{array}$} \\
\hline Gender of & male & $22(59.5 \%)$ & $20(69.0 \%)$ & $39(68.4 \%)$ & $38(79.2 \%)$ & $119(69.6 \%)$ & \\
\hline participants & female & $15(40.5 \%)$ & $9(31.0 \%)$ & $18(31.6 \%)$ & $10(20.8 \%)$ & $52(30.4 \%)$ & 0.263 \\
\hline \multirow{3}{*}{$\begin{array}{l}\text { Marital status } \\
\text { of participants }\end{array}$} & married & $0(0.0 \%)$ & $0(0.0 \%)$ & $2(3.5 \%)$ & $2(4.2 \%)$ & $4(2.3 \%)$ & \multirow{3}{*}{0.544} \\
\hline & Single & $36(97.3 \%)$ & $29(100.0 \%)$ & 55 (96.5\%) & 46 (95.8\%) & $166(97.1 \%)$ & \\
\hline & divorced & $1(2.7 \%)$ & $0(0.0 \%)$ & $0(0.0 \%)$ & $0(0.0 \%)$ & $1(0.6 \%)$ & \\
\hline \multirow{3}{*}{ Residency of participants } & Riyadh & $5(13.5 \%)$ & $11(37.9 \%)$ & $10(17.5 \%)$ & $15(31.3 \%)$ & $41(24.0 \%)$ & \multirow{3}{*}{0.097} \\
\hline & Majmaah & $19(51.4 \%)$ & $15(51.7 \%)$ & $33(57.9 \%)$ & $25(52.1 \%)$ & $92(53.8 \%)$ & \\
\hline & Others & $8(21.6 \%)$ & $2(6.9 \%)$ & $4(7.0 \%)$ & $4(8.3 \%)$ & $18(10.5 \%)$ & \\
\hline \multirow{4}{*}{ Academic year } & 2nd & $16(43.2 \%)$ & $9(31.0 \%)$ & $9(15.8 \%)$ & $16(33.3 \%)$ & $50(29.2 \%)$ & \multirow{4}{*}{0.144} \\
\hline & $3 \mathrm{rd}$ & $9(24.3 \%)$ & $8(27.6 \%)$ & $20(35.1 \%)$ & $14(29.2 \%)$ & $51(29.8 \%)$ & \\
\hline & 4th & $7(18.9 \%)$ & $9(31.0 \%)$ & $13(22.8 \%)$ & 7 (14.6\%) & $36(21.1 \%)$ & \\
\hline & 5 th & $5(13.5 \%)$ & $3(10.3 \%)$ & 15 (26.3\%) & $11(22.9 \%)$ & $34(19.9 \%)$ & \\
\hline
\end{tabular}




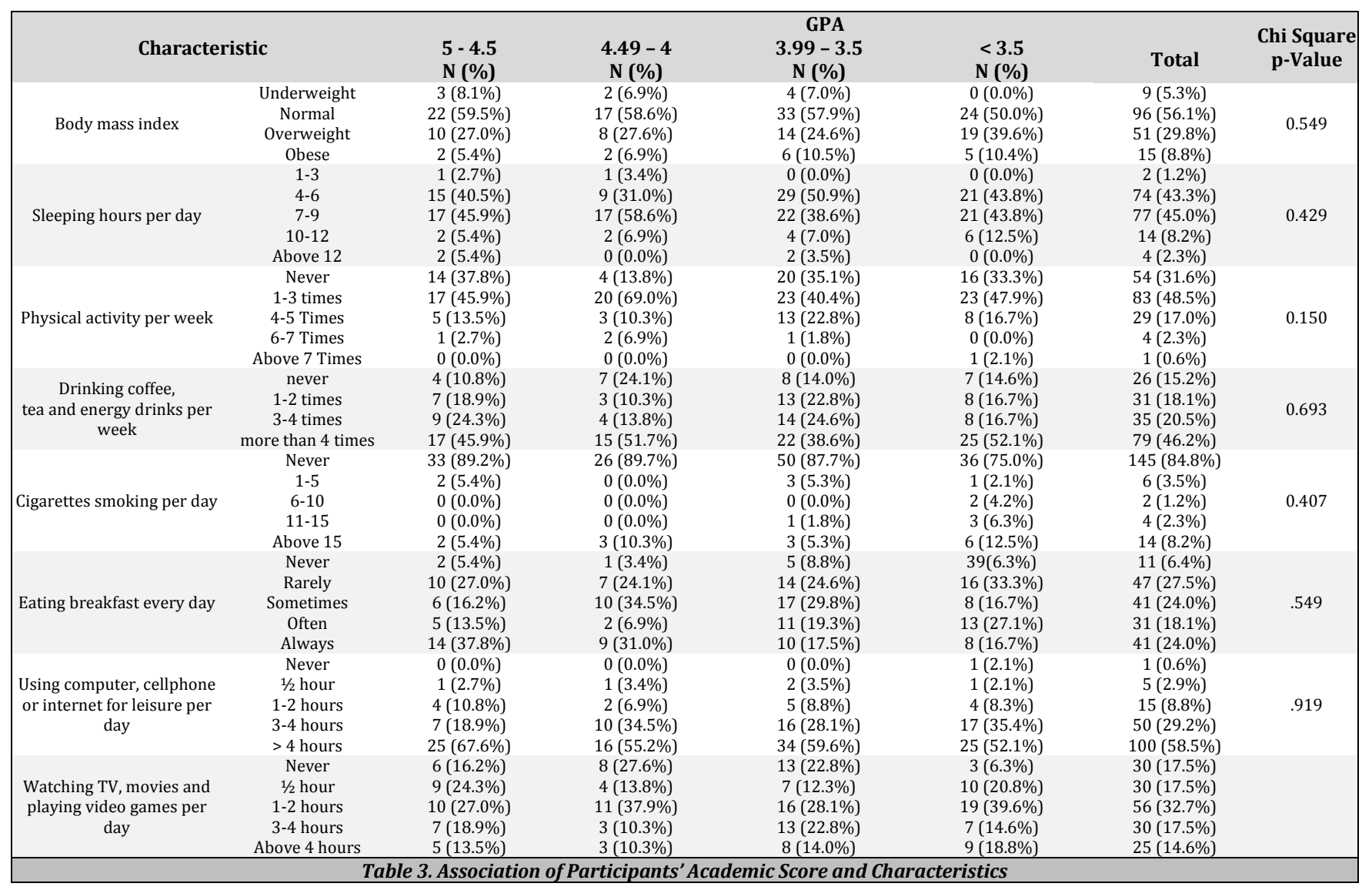

Table-3 of our study showed that out of the 37 who scored GPA 5 - 4.5, 3 (8.1\%) their BMI was underweight, 22 $(59.5 \%)$ were normal, $10(27 \%)$ were overweight, and 2 (5.4\%) were obese and those whom GPA <3.5, 24 (50\%) of them reported that they have normal BMI, 19 (39.6\%) were overweight, $5(10.4 \%)$ were obese, and none of them was underweight. As can be seen in table-4, those who have GPA 5-4.5 and sleeping 7-9 hours per day were 17 (45.9\%), 15 $(40.5 \%)$ were sleeping 4-6 hours per day, 2 (5.4\%) were sleeping 10-12 hours per day, 2 (5.4\%) were sleeping more than 12 hours per day, and only $1(2.7 \%)$ was sleeping $1-3$ hours per day and out of those who have GPA <3.5, 21 $(43.8 \%)$ were sleeping 7-9 hours per day, 21 (43.8\%) were sleeping 4-6 hours per day, 6 (12.5\%) were sleeping 10-12 hours per day, and none was sleeping more than 12 hours or 1-3 hours per day. Regarding physical activity, out of those who have GPA 5-4.5, 14 (37.8\%) they never engage in any physical activity, 17 (45.9\%) they have 1-3 times of physical activity per week, 5 (13.5\%) they have 4-5 Times of physical activity per week, 1 (2.7\%) reported having 6-7 Times of physical activity per week, and none of the respondents reported having more than seven times of physical activity per week. In the other hand, 17 (45.9\%) of those who have GPA 5-4.5 were drinking coffee, tea and energy drinks more than 4 times per week, 9 (24.3\%) were drinking 3-4 times per week, 7 (18.9\%) were drinking 1-2 times per week and 4 $(10.8 \%)$ never have coffee, tea or energy drinks and out of those with GPA <3.5, 25 (52.1\%) were taking coffee, tea and energy drinks more than 4 times per week, 8 (16.7\%) were taking coffee, tea and energy drinks 3-4 times per week, 8 $(16.7 \%)$ were taking coffee, tea and energy drinks 1-2 times per week and 7 (14.6\%) never have coffee, tea and energy drinks.
Regarding smoking, 33 (89.2\%) of those who have GPA 54.5 reported that they never smoke, 2 (5.4\%) were smoking 1-5 cigarettes per week, $2(5.4 \%)$ were smoking more than 15 cigarettes per day and large number $36(75.0 \%)$ of those with GPA $<3.5$ said that they also never smoke, $1(2.1 \%)$ were smoking 1-5 cigarettes per day, 2 (4.2\%) were smoking 6-10 cigarettes per day, $3(6.3 \%)$ were smoking 11-15 cigarettes per day and $6(12.5 \%)$ were smoking more than 15 cigarettes per day. 14 (37.8\%) of those with GPA 5-4.5 always had breakfast every day, $5(13.5 \%)$ they often had breakfast every day, $6(16.2 \%)$ they sometimes had breakfast every day, 10 $(27.0 \%)$ they rarely had breakfast every day,2 (5.4\%) never had breakfast on any day and $16(33.3 \%)$ of those with GPA $<3.5$ said that they rarely had breakfast on every day, 8 (16.7\%) always had breakfast every day, 13 (27.1\%) often had breakfast on every day, $8(16.7 \%)$ sometimes had breakfast on every day and $3(6.3 \%)$ never had breakfast on any day. 25 (67.6\%) of those with GPA 5-4.5 they are Using computer, cell phone or internet for leisure more than 4 hours per day, 7 (18.9\%) are Using computer, cell phone or internet for leisure 3-4 hours per day, $4(10.8 \%)$ are Using computer, cell phone or internet for leisure 1-2 hours per day, $1(2.7 \%)$ is Using computer, cell phone or internet for leisure for half hour per day and $25(52.1 \%)$ of those who have GPA $<3.5$ are Using computer, cell phone or internet for leisure more than 4 hours per day, 17 (35.4\%) are Using computer, cell phone or internet for leisure 3-4 hours per day, 4 (8.3\%) are Using computer, cell phone or internet for leisure $1-2$ hours per day, $1(2.1 \%)$ is Using computer, cell phone or internet for leisure for half hour per day and 1 $(2.1 \%)$ is never Using computer, cell phone or internet for leisure. $5(13.5 \%)$ of the participants who have GPA 5-4.5 are Watching TV, movies and playing video games more than 4 
hours per day, 7 (18.9\%) are Watching TV, movies and playing video games 3-4 hours per day, 10 (27.0\%) are Watching TV, movies and playing video games 1-2 hours per day, 9 (24.3\%) are Watching TV, movies and playing video games for half an hour per day and $6(16.2 \%)$ are never Watching TV, movies and playing video games and 9 (18.8\%) of the participants who have GPA $<3.5$ are Watching TV, movies and playing video games more than 4 hours per day, 7 (14.6\%) are Watching TV, movies and playing video games 34 hours per day, 19 (39.6\%) are Watching TV, movies and playing video games 1-2 hours per day, 10 (20.8\%) are Watching TV, movies and playing video games for half an hour per day and $3(6.3 \%)$ are never watching TV, movies and playing video games.

\section{DISCUSSION}

This study was conducted to explore the association between lifestyle and the students' academic performance. Our research findings highlighted that there is no significant association. A review of the literature showed that not all studies had found a considerable association between lifestyle and academic performance. In comparing the size of the sample, our study had 171 samples, whereas the research conducted by Tongeholte(7) among Norwegian adolescents had a large sample size of 2432 samples. Another study conducted by Eun Sun So ${ }^{(8)}$ among Korean adolescents had a sample size of 76980 . Both of these results showed a positive association between lifestyle and academic performance.

In contrast, because of the small sample size, our research findings failed to prove a positive association. There is significant evidence documenting a positive association between a healthy lifestyle and academic achievement, but a vast majority focuses on primary and high school adolescents. Fewer studies document this trend when students transition from adolescent to adult life. A survey conducted by Jesse Calestine et al. highlights this trend and concludes that in university students, there is an overall decline in physical activity levels and a change in dietary habits attributed to a variety of factors. When students move from high school to college, they gain greater flexibility and autonomy in their lives, and they require greater time demand, which restricts physical activities and influences dietary habits.(9) Similar to our results, one research carried out among medical students found that there was no association between academic achievement and body mass index.(10) Another study found that physical activity was associated with higher cognitive performance in early teens, but in later years, the most active adult had a lower cognitive performance. This highlights a possible shift in the relationship of healthy lifestyle with academic performance as a person ages.(11) Furthermore, another study found that increased academic load is associated with weight gain.(12) The students in medical college require more effort to achieve excellent academic progress compared to school and college going adolescents. Our research focuses on medical students in the age group of 21-25 years.
Our study did not show any association between sleeping hours and academic performance. In contrast, the optimal sleeping hours per night is an essential parameter in a healthy lifestyle, which will lead to excellent academic performance, and those who have sleeping hours less or more than optimal sleeping hours have a poor academic achievement. $(3,7,9,13$, and 14) There was also no connection between body mass index and academic performance in our research findings, which is similar to the study conducted by Khalid A Alswat et al,(14) in Saudi Arabia. Besides, there was no association between the quality and quantity of food, including junk food consumption and academic performance in our research. This also matches the finding of the study conducted by McIsaac JL et al.(3) and Khalid A Alswat et al,(14) unlike other studies that showed a positive association between diet and junk food consumption and academic achievement. Our study also showed that there is no association of physical activity with academic performance. This result is consistent with the findings of other researchers, McIsaac JL et al.(3) and Khalid A Alswat et al.(14). In contrast, other studies show that a moderate level of physical activity is strongly correlated with excellent academic achievement. $(7,8)$

Finally, no association between academic performance and substance abuse was noted in our study. In contrast, a large-scale study in Korea in 2016 showed that there is an association between alcohol consumption and smoking and low academic performance and an association between regular diet, quitting smoking and alcohol consumption, improving academic performance. ${ }^{[8]}$ Another study done in 2007 showed that the extensive use of cigarettes, alcohol, and marijuana is more prevalent in poor academic achievers as compared to students who do not participate in these substance use behaviours.[10] Saudi Arabia is a conservative country, and many participants come from a religious background. They do not have access to many of the intoxicants apart from cigarette smoking, so this aspect of the study failed to provide any meaningful result.

\section{CONCLUSIONS}

There was no correlation between lifestyle such as, BMI, sleeping hours, physical activity, drinking coffee, tea and energy drinks, cigarettes smoking, eating breakfast, using a computer, cell phone or internet for leisure per day, watching tv, movies and playing video games per day and school performance. There is a need for further studies on a larger sample of participants.

\section{ACKNOWLEDGEMENT}

The author would like to thank Deanship of Scientific Research of Majmaah University for supporting this work under Project Number 08342/06. 


\section{REFERENCES}

[1] World Health Organization. Regional Office for Europe. 1999. Healthy living: what is a healthy lifestyle? Copenhagen: WHO Regional Office for Europe. http://www.who.int/iris/handle/10665/108180

[2] Heidari M, Borujeni MB, Borujeni MG, et al. Relationship of lifestyle with academic achievement in nursing students. Journal of Clinical and Diagnostic Research 2017;11(3):JC01-JC03.

[3] McIsaac JLD, Kirk SFL, Kuhle S. The association between health behaviours and academic performance in Canadian elementary school students: a cross-sectional study. International Journal of Environmental Research and Public Health 2015;12(11):14857-71.

[4] Definition of Lifestyle. Business Directory. [http://www.businessdictionary.com/definition/lifestyl e.html.]

[5] Mahmood FM. Prevalence and prevention of lifestylerelated diseases in Saudi Arabia. Int J Health Sci (Qassim) 2018;12(5):1-2.

[6] NCD Risk Factor Collaboration (NCD-RisC). Worldwide trends in body-mass index, underweight, overweight, and obesity from 1975 to 2016: a pooled analysis of 2416 population-based measurement studies in 128.9 million children, adolescents and adults. Lancet 2017;390(10113):2627-42.
[7] Stea TH, Torstveit MK. Association of lifestyle habits and academic achievement in Norwegian adolescents: a cross-sectional study. BMC Public Health 2014;14:829.

[8] So ES, Park BM. Health behaviors and academic performance among Korean adolescents. Asian Nurs Res (Korean Soc Nurs Sci) 2016;10(2):123-7.

[9] Calestine J, Bopp M, Bopp CM, et al. College student work habits are related to physical activity and fitness. Int J Exerc Sci 2017;10(7):1009-17.

[10] Agarwal S, Bhalla P, Kaur S, et al. Effect of body mass index on physical self-concept, cognition \& academic performance of first year medical students. Ind J Med Res 2013;138(4):515-22.

[11] Esteban-Cornejo I, Hallal PC, Mielke GI, et al. Physical activity throughout adolescence and cognitive performance at 18 years of age. Med Sci Sports Exerc 2015;47(12):2552-7.

[12] Economos CD, Hildebrandt ML, Hyatt RR. College freshman stress and weight change: differences by gender. Am J Health Behav 2008;32(1):16-25.

[13] Shi X, Tubb L, Fingers ST, et al. Associations of physical activity and dietary behaviors with children's health and academic problems. Journal of School Health 2013;83(1):1-7.

[14] Alswat KA, Al-Shehri AD, Aljuaid TA, et al. The association between body mass index and academic performance. Saudi Medical Journal 2017;38(2):186-91. 